\title{
Prevalence and incidence of thyroid disorder during pregnancy in Bangladesh - a tertiary care hospital based study
}

\author{
Shahid M M ${ }^{1}$, Ferdousi $\mathrm{S}^{2}$ \\ ${ }^{1}$ Department of Endocrinology, Ad-din women's Medical college, Mogbazar, Dhaka. \\ ${ }^{2}$ Department of Pathology, Dr. Sirajul Islam Medical College, Mogbazar, Dhaka.
}

\section{Abstract}

Objectives: To establish the prevalence and incidence of thyroid dysfunction during pregnancy in a tertiary care center in Bangladesh.

Methodology: 749 cases were randomly selected among the pregnant women who reported to antenatal clinic. Later 121 women were excluded as they were already diagnosed cases of thyroid disorder. The rest were investigated for thyroid stimulating hormone (TSH) and if required then they were also investigated for free triiodothyronine (FT3), free thyroxine (FT4), and thyroid peroxidase antibody (TPOAb). Thyroid status was classified according to TSH level euthyroidism, subclinical hypothyroidism, overt hypothyroidism and hyperthyroidism (sub-clinical hyperthyroidism, Graves' disease/toxic multinodular goiter, transient hyperthyroidism of pregnancy). And all patients were divided into 2 groups - normal/euthyroidism and abnormal/thyroid disorder, considering their thyroid status.

Result: The prevalence of thyroid disorder during pregnancy was $34.98 \%$ and incidence was $22.45 \%$. The mean TSH levels $(\mu \mathrm{IU} / \mathrm{mL})$ of $1^{\text {st }}, 2^{\text {nd }}$ and $3^{\text {rd }}$ trimester were $2.67 \pm 3.59,2.39 \pm 1.87$ and $2.74 \pm 3.98$, respectively. Significant number of overt hypothyroid cases were detected among rural people $(\mathrm{P}-0.004)$. There were significant difference of incidence of euthyroid $(\mathrm{P}-0.029)$ and SCHTh $(\mathrm{P}-0.031)$ cases at different stages of gestation. There were also significant number of cases with goiter $(\mathrm{P}-<0.001)$ and TPOAb $(\mathrm{P}-<0.001)$ in different patient groups.

Conclusion: Thyroid disorders are common in pregnancy. Early detection and proper treatment of thyroid dysfunction can help for better outcome. Hence, thyroid function test must be advised to all pregnant women.

Keywords: Pregnancy, euthyroidism, subclinical hypothyroidism, overt hypothyroidism and hyperthyroidism.

Correspondence email: dr.ms952@gmail.com

(iD) https://orcid.org/0000-0003-4797-2686

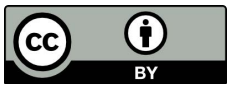

This is an open-access article distributed under the terms of the Creative Commons Attribution License, which permits unrestricted use, distribution, and reproduction in any medium, provided the original author and source are credited (CC BY 4.0) 


\section{Introduction}

Pregnancy is a physiological condition where thyroid hormone has a significant role to play as it is necessary for fetal development and maturation. Thyroid diseases have strong predominance in woman of childbearing age and pregnancy is often associated with thyroid dysfunction. Thyroid disorders (TD) are the second most common endocrine disorders affecting women in the reproductive period ${ }^{(1)}$. A normal pregnancy undergoes a number physiological changes which are followed by alteration of thyroid and other hormonal status ${ }^{(2)(3)}$. It is not uncommon that thyroid dysfunction goes unnoticed during pregnancy because of the nonspecific symptoms. As fetus is dependent on maternal thyroid hormone supply until the end of $1^{\text {st }}$ trimester, a poorly managed hypothyroid mother can give birth a child of low intelligence ${ }^{(3)(4)}$. The risk of miscarriage is increased in autoimmune thyroid disease ${ }^{(4)}$. Maternal Graves' disease (GD) can lead to pregnancy loss as well as fetal thyroid dysfunction. Hyperthyroidism occurs in $0.2 \%-0.4 \%$ of pregnant women and is most commonly associated with $\mathrm{GD}^{(5)}$. Prevalence of hypothyroidism during pregnancy varies from $2.5 \%$ to $11 \%$ according to geographic distribution ${ }^{(6)}$. The prevalence of hypothyroidism is higher in Asia compared to the West (6). In pregnancy, $0.2 \%$ and $2.3 \%$ cases are diagnosed as overt hypothyroidism and sub-clinical hypothyroidism, respectively ${ }^{(6)}$. The aim of this study is to estimate the prevalence and incidence of thyroid disorder of pregnant women, reported in the out-patient department of a tertiary care hospital in Bangladesh.

\section{Material and methods}

This cross sectional study was conducted from $1^{\text {st }}$ December, 2018 to $30^{\text {th }}$ November, 2019 at Ad-din women's medical college, a tertiary care hospital. Amongst all pregnant women who reported to antenatal clinic, 749 women were randomly selected after obtaining written informed consent irrespective of their gestational age and gravida status. They were subjected to clinical evaluation with emphasis on the family history of thyroid disorder and presence of thyroid gland enlargement. Subjects' area of residence were documented and divided into 3 zones - urban (city corporation area), suburban (city corporation adjacent areas, district towns), rural (rest other area).

\section{Inclusion Criteria:}

$\checkmark$ All pregnant women reported to antenatal clinic.

\section{Exclusion Criteria:}

$\checkmark$ Pregnant women with established thyroid disorders.

$\checkmark$ Subjects with history of taking drugs which affect thyroid function.

E.g. Lithium, prednisolone, amiodarone.

$\checkmark$ Subjects with any disease which may alter thyroid status.

E.g. Mumps virus infection, Adeno virus infection.

121 women were excluded as they were already diagnosed cases of TD. Rest of the subjects were investigated for thyroid stimulating hormone (TSH) and in case of any diagnostic dilemma/abnormality, free triiodothyronine (FT3), free thyroxine (FT4), and thyroid peroxidase antibody (TPOAb) were estimated too. Although total triiodothyronine (TT3) and total thyroxine (TT4) measurement is more reliable during pregnancy and FT3, FT4 widely vary during 
pregnancy between different methods, yet we recommended FT3 and FT4 as TT3, TT4 levels are reliable during last stage of pregnancy (TT4 reaches the steady level after 16 weeks of pregnancy) ${ }^{(7)}$. But we had patients of different stages of pregnancy and they were only advised for FT3 and FT4 whenever there were diagnostic dilemma regarding the type of hyperthyroidism; which we mostly faced during the early stage of pregnancy. Thyroid status was classified according to TSH value - euthyroidism, subclinical hypothyroidism (SCH), overt hypothyroidism (O.HypoTh) and hyperthyroidism - sub-clinical hyperthyroidism (SCHTh), Grave's disease (GD)/ toxic multinodular goiter (TMG), transient hyperthyroidism of pregnancy (THP). Patients were divided into 2 groups normal/euthyroid and abnormal/ thyroid disorder (SCH, O.HypoTh, GD/TMG, SCHTh and THP). According to American Thyroid Association (ATA) and hospital laboratory reference value, pregnant woman with TSH 0.35 - $3.99 \mu \mathrm{IU} / \mathrm{mL}$ was considered as euthyroid. Isolated hypothyroxinemia is defined as normal maternal TSH concentration in conjunction with FT4 levels in the lower $2.5^{\text {th }}-5^{\text {th }}$ percentile of the reference range ${ }^{(7)}$. Considering normal TSH value, patients of isolated hypothyroxinemia were grouped as euthyroid.
In $\mathrm{SCH}$ state, TSH was in the range of $4.0-$ $9.9 \mu \mathrm{IU} / \mathrm{mL}$ and O.HypoTh was considered when $\mathrm{TSH}$ was $\geq 10 \mu \mathrm{IU} / \mathrm{mL}(7)$. If TSH is $<0.35 \mu \mathrm{IU} / \mathrm{mL}$; FT4, FT3 and TSH receptor antibody (TRAb) is elevated, then diagnosis is GD. It is the most common cause of hyperthyroidism in women of childbearing age. But if TRAb is negative but $\beta$-human chorionic gonadotropin (hCG) level is elevated (above the laboratory reference range), then diagnosis is THP. THP usually resolves spontaneously by $14-18$ weeks of gestation $^{(7)}$. If TSH is $<0.35 \mu \mathrm{IU} / \mathrm{mL}$, TRAb is negative $\beta$-hCG low/normal, then possibility of other causes of hyperthyroidism needs to be evaluated .e.g. TMG .SCHTh is diagnosed if TSH is $<0.35$ $\mu \mathrm{IU} / \mathrm{mL}$ but FT4, FT3 are normal. But it is clinically insignificant during pregnancy ${ }^{(7)}$.

TSH, FT4, FT3, TPOAb, $\beta$ were analyzed by using emiluminescent sequential immunometric assay with IMMULITE 1000 immunoassay analyzer.

Statistical analysis was done using SPSS 23 software. The categorical variables were represented as percentages and measurable variables as mean \pm SD. One way - ANOVA test and Chi-square test were performed for comparing the variables between different groups as appropriate. $\mathrm{P}$ value $<0.05$ was considered to be significant. 
Results

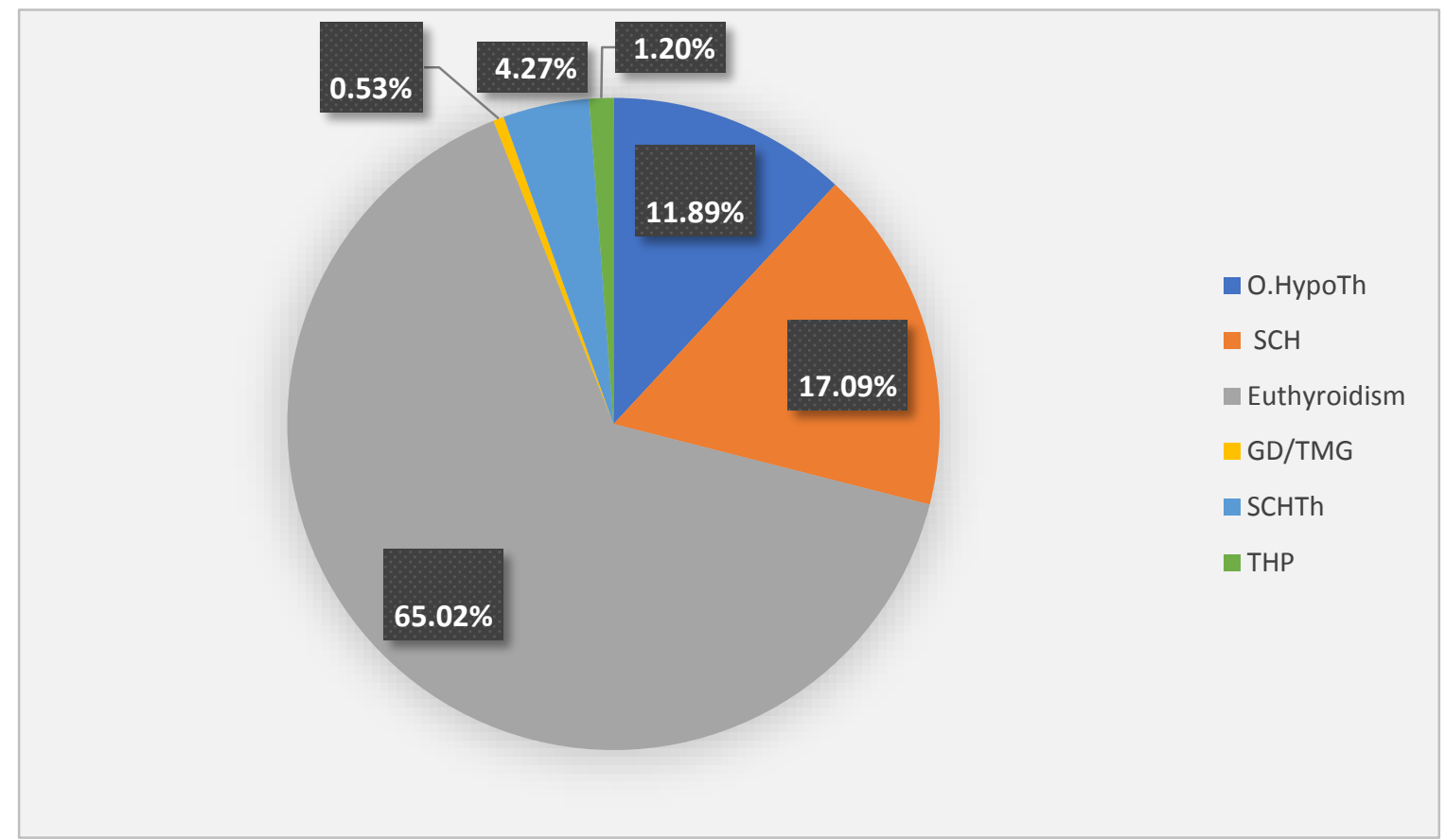

Figure 1: Prevalence of thyroid disorder during pregnancy.

The prevalence of thyroid disorder during pregnancy was $34.98 \%(n=749)$.

Table 1: Baseline clinical characteristics and comparison amongst different groups

\begin{tabular}{|c|c|c|c|c|c|}
\hline \multirow[t]{2}{*}{ Variables } & \multicolumn{2}{|l|}{ Age } & \multicolumn{2}{|l|}{ Residence } & \multirow[t]{2}{*}{$P$ value } \\
\hline & $\begin{array}{l}\text { (Mean } \pm \\
\text { SD) }\end{array}$ & Urban & Sub-urban & Rural & \\
\hline Euthyroidism & $27.73 \pm 4.39$ & 317 & 84 & 86 & 0.178 \\
\hline $\mathrm{SCH}$ & $27.13 \pm 4.30$ & 62 & 11 & 16 & 0.465 \\
\hline $\begin{array}{l}\text { Overt } \\
\text { hypothyroidism }\end{array}$ & $26.40 \pm 3.03$ & 3 & 1 & 6 & 0.004 \\
\hline GD/ TMG & 33 & 1 & 0 & 0 & 0.759 \\
\hline SCHTh & $\begin{array}{l}27.09 \\
4.298\end{array}$ & 18 & 4 & 10 & 0.195 \\
\hline THP & $\begin{array}{l}23.89 \\
3.856\end{array}$ & 4 & 3 & 2 & 0.331 \\
\hline
\end{tabular}


Table 2: Thyroid hormone status in different trimester

\begin{tabular}{|c|c|c|c|c|c|}
\hline Variables & $1^{\text {st }}$ trimester & $2^{\text {nd }}$ trimester & $3^{\text {rd }}$ trimester & Total & $\mathbf{P}$ value \\
\hline TSH $(\mu \mathrm{IU} / \mathrm{mL})$ & $2.67 \pm 3.6$ & $2.39 \pm 1.87$ & $2.74 \pm 3.98$ & $2.56 \pm 3.03$ & 0.384 \\
\hline \multicolumn{6}{|l|}{ Mean \pm SD } \\
\hline Euthyroidism & $133(21.17)$ & $234(37.26)$ & $120(19.1)$ & 487 & 0.029 \\
\hline $\mathbf{N}(\%)$ & & & & $(77.54)$ & \\
\hline $\mathrm{SCH}$ & $29(4.61)$ & $43(6.84)$ & $17(2.7)$ & 89 (14.17) & 0.601 \\
\hline \multicolumn{6}{|l|}{$\mathbf{N}(\%)$} \\
\hline O.НypoTh & $4(0.63)$ & $2(0.31)$ & $4(0.63)$ & $10(1.59)$ & 0.202 \\
\hline \multicolumn{6}{|l|}{ N ( $\%)$} \\
\hline GD/TMG & 0 & $1(0.159)$ & 0 & $1(0.159)$ & 0.570 \\
\hline \multicolumn{6}{|l|}{ N (\%) } \\
\hline SCHTh & $16(2.54)$ & $12(1.91)$ & $4(0.63)$ & $32(5.09)$ & 0.031 \\
\hline \multicolumn{6}{|l|}{ N (\%) } \\
\hline THP & $5(0.79)$ & $4(0.63)$ & 0 & $9(1.43)$ & 0.125 \\
\hline $\mathbf{N}(\%)$ & & & & & \\
\hline
\end{tabular}

Table 3: comparison between euthyroidism and thyroid disorder

\begin{tabular}{lllll}
\hline Variable & Euthyroidism & $\begin{array}{l}\text { Thyroid } \\
\text { disorder }\end{array}$ & Total & P value \\
\hline $\begin{array}{l}\text { Family history } \\
\text { of TD }\end{array}$ & 36 & 17 & 53 & 0.79 \\
TPOAb & 25 & 26 & 51 & $<0.001$ \\
Goiter & 9 & 21 & 30 & $<0.001$ \\
\hline
\end{tabular}

The mean age of all groups was 25 years. The incidence of TD was higher among urban dwellers but incidence of overt hypothyroidism was significantly higher among rural people (P-0.004).

The incidence of TD during pregnancy was
$(22.45 \%, \mathrm{n}=628)$. Among TD, the incidence of SCH $(14.17 \%)$ was the highest. There were significant difference of incidence of euthyroid (P - 0.029) and SCHTh (P - 0.031) cases at different stages of gestation.

Presence of family history of thyroid disorder 
(P - 0.79) in euthyroidism and Thyroid disorder group wasn't significantly different. There were significant difference of goiter $(\mathrm{P}$ - <0.001) and TPOAb ( $-<0.001)$ positive cases in both groups.

\section{Discussion}

In this study, the prevalence of thyroid disorder during pregnancy was 34.98\% ,which was higher than Akram FH et al. ${ }^{(8)}$. The prevalence of hypothyroidism (overt and $\mathrm{SCH})$ was $28.98 \%$ which was higher comparing to Chandrasekhara $P$ et al ${ }^{\left({ }^{(}\right)}$. The geographical position of Bangladesh might have an important role behind this ${ }^{(9)(10)}$.

The incidence of thyroid disorder during pregnancy was $22.45 \%$ - O.HypoTh $(1.60 \%), \quad \mathrm{SCH} \quad(14.17 \%) \quad$ and Hyperthyroidism (6.68\%). The incidence of euthyroidism was $77.55 \%$. In this study, we have found significant number of euthyroid (P-0.029) and hyperthyroid (P-0.006) cases during different trimesters of gestation but difference of the numbers of SCH (P-0.601) and O.HypoTh (0.202) cases wasn't of that significance. Mean TSH $(\mu \mathrm{IU} / \mathrm{mL})$ of $1^{\text {st }}$, 2nd and $3^{\text {rd }}$ trimesters were $2.67 \pm 3.59$, $2.39 \pm 1.87,2.74 \pm 3.98$, respectively, though the differences among the trimesters weren't significant (P- 0.384).

Patients of O.HypoTh and SCH were treated with levothyroxine. Euthyroid (TSH 2.6$3.99 \mu \mathrm{IU} / \mathrm{mL}$ ) patients but TPOAb positive were also considered for levothyroxine treatment if they had history of unexplained pregnancy loss and that was done after assessing the risk-benefit outcome ${ }^{(7)}$. Euthyroid patients with TSH $.35-2.5$ $\mu \mathrm{IU} / \mathrm{mL}$ irrespective of TPOAb status, patients with isolated hypothyroxinemia, THP and SCHy.Th weren't considered for treatment but were advised to check serum TSH level on regular interval ${ }^{(7)}$. Patients with hyperthyroidism (GD and TMG) were treated with anti-thyroid drugs (carbimazole and propylthiouracil) ${ }^{(7)}$.

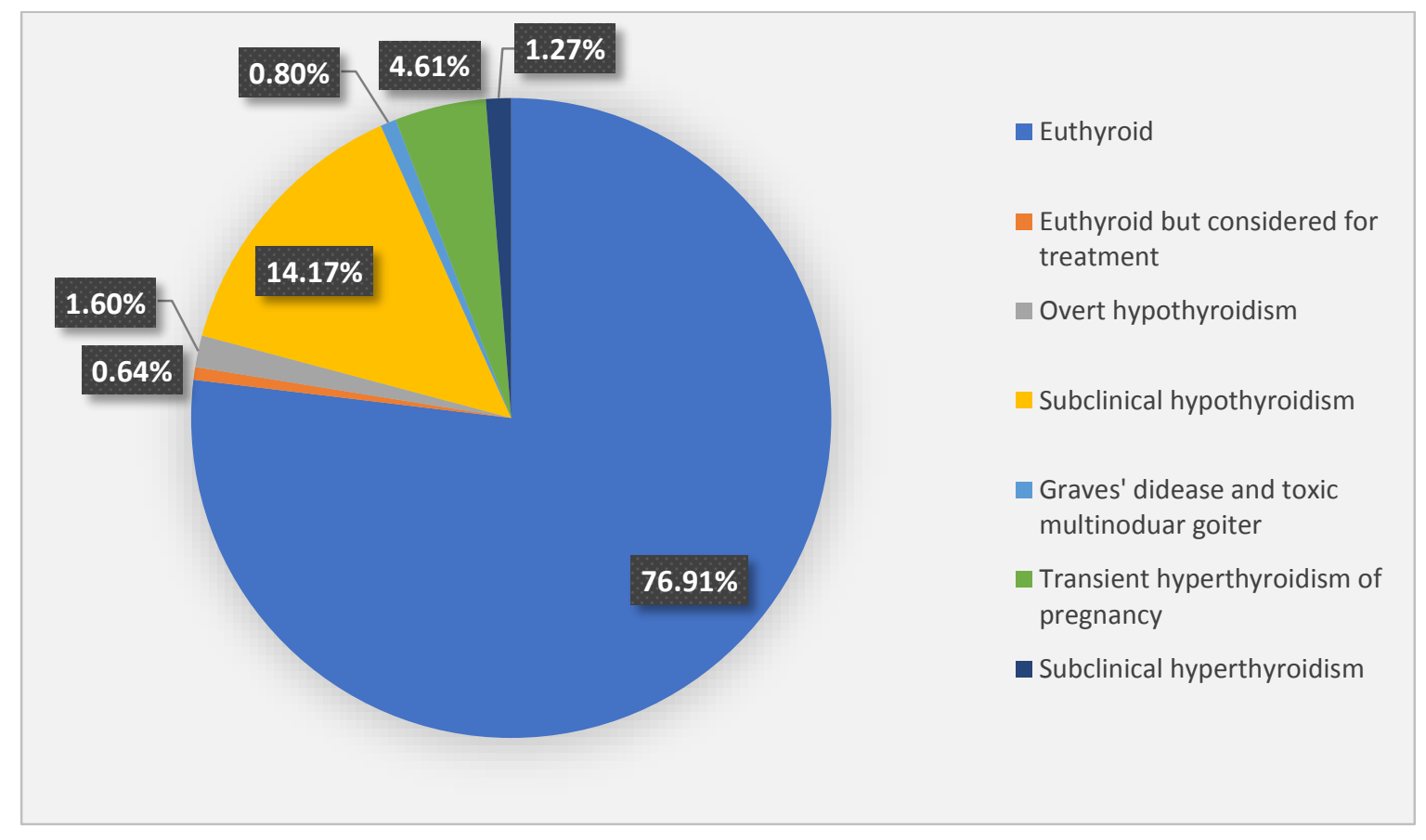

Figure 2: Thyroid status during pregnancy. 
According to Potlukova E et al., age of pregnant women isn't related to prevalence of autoimmune thyroid disorders ${ }^{(11)}$. This study had the similar result as the mean age of patients of different thyroid status groups; it was mostly indifferent, 25 years.

Residence has great importance regarding the prevalence and incidence of thyroid disorders $^{(12)(13)}$. Although most of the people of our country live in rural area, this study reported that most of the reported cases of TD were hailed from urban area. Social awareness, education, and good communication facilities were the main reasons behind this. The effect of urban pollution should be acknowledged as well.

In this study, there were significant associations of presence of TPOAb (P$<0.001)$ and goiter $(\mathrm{P}-<0.001)$ with different thyroid status during pregnancy. But it failed to show any significant difference regarding the association of positive family history of TD (P-0.79) with various thyroid status.

The measurement of TPOAb does not give any indication of thyroid status but its presence does have important implications for the pregnancy. In 2011 a meta-analysis considering 12,126 patients, found that women with TPOAb had a 4-fold increased risk of miscarriage according to cohort studies; and a 1.8-fold increased risk according to case-control studies ${ }^{(14)}$. TPOAb is also associated with an increased risk of preterm delivery ${ }^{(15)}$. Even the presence of TPOAb at late weeks gestation can result in a significant IQ decrement in children of euthyroid mothers ${ }^{(16)}$. TPOAb positive women are associated with the risk decreased thyroid functional reserve during gestation which may result in overt hypothyroidism ${ }^{(17)}$. Besides that, they are at high risk of developing postpartum thyroiditis ${ }^{(18)}$.
Pregnancy is a physiological condition where goiter may be present due to increased demand $^{(19)}$. Besides, women are always at higher risk of TD and goiter ${ }^{(20)}$. Positive family history of TD is also a risk factor for TD which should be considered during pregnancy with great importance despite our failure to show any significant relation with thyroid status in pregnancy ${ }^{(21)(22)}$.

One of the limitations of this study was that we only focused on TSH value, though it is recommended to check full thyroid hormone profile before initiating treatment, especially for hyperthyroidism ${ }^{(7}$ ). But because of the lack of trimester specific normal values for FT4, FT3 we decided to do so. Some of the cases failed to provide their thyroid antibody reports and information regarding family history. We only considered TPOAb because anti thyroglobulin antibody detection was not recommended by ATA during pregnancy and also because of limited availability of TRAb testing facility in our country ${ }^{(7)}$. In this study, we didn't follow up the patients throughout the gestational period. It would have been more appropriate had we included the data regarding the change of thyroid status and outcome, since we conducted a prevalence and incidence study.

\section{Conclusion}

This study has demonstrated high prevalence $(16.15 \%)$ and incidence $(23.57 \%)$ of TD. $\mathrm{SCH}$ has the highest incidence rate among TD. TPOAb (P-<0.001). Family history of TD $(\mathrm{P}-<0.001)$ was significantly associated with thyroid status during pregnancy. These indicate the necessity of extensive thyroid screening during pregnancy so that early diagnosis and management can be done which will eventually make a huge difference in pregnancy outcome. 


\section{Reference}

1. Negro R, Mestman JH. Thyroid disease in pregnancy. Best Pract Res Clin Endocrinol Metab. 2011 Dec;25(6):927-43

2.Moleti M, Trimarchi F, Vermiglio F. Thyroid physiology in pregnancy. Endocr Pract. 2014 Jun;20(6):589-96.

3.Cignini P, Cafà EV, Giorlandino C, Capriglione S, Spata A, Dugo N. Thyroid physiology and common diseases in pregnancy: review of literature. J Prenat Med. 2012;6(4):64-71.

4. Lazarus JH. Thyroid disease in pregnancy and childhood. Minerva Endocrinol. 2005 Jun;30(2):71-87.

5. Dülek H. The Prevalance of Thyroid Dysfunction and Relationship with Perinatal Outcomes in Third Trimester Pregnants Who Apply to Tertiary Center. North Clin Istanbul. 2018;6(3):267-72.

6. Chandrasekhara P, Aslam M, Kala K, Sultana F. A Study of Thyroid Disorder During Pregnancy. A Study Thyroid Disord Dur Pregnancy. 2016;(July 2015):1-6.

7. Alexander EK, Pearce EN, Brent GA, Brown RS, Chen H, Dosiou C, et al. 2017 Guidelines of the American Thyroid Association for the Diagnosis and Management of Thyroid Disease during Pregnancy and the Postpartum. Thyroid. 2017;27(3):315-89.

8. Akram FH, Johansson B, Möllerström G, Landgren BM, Stavreus- Evers A, SkjöldebrandSparre L. Incidence of Subclinical Hypothyroidism and Hypothyroidism in Early Pregnancy. J Women's Heal. 2017;26(11):1231-5.

9. Spallholz JE, Boylan LM, Rahman MM, Katz $\mathrm{D}$, Robertson JD, Zakaria ABM, et al. Seleniumcontent of rice, mixed plant foods and fish from Bangladesh. Toxicol Environ

Chem. 2008;90(2):211-20.

10. Hossain MF. Arsenic contamination in
Bangladesh - An overview. Agric Ecosyst Environ. 2006;113(1-4):1-16.

11.Potlukova E, Potluka O, Jiskra J, Limanova Z, Telicka Z, Bartakova J, et al. Is age a risk factor for hypothyroidism in pregnancy? An analysis of 5223 pregnant women. J Clin Endocrinol Metab. 2012; 97(6): 1945-52.

12.Castillo-Duran C. Epidemiology of Micronutrient Deficiencies in Developing and Developed Countries, Specifically Zinc, Copper, Selenium and Iodine. Micronutr Defic Dur Weaning Period First Years Life.

2004;54(table 1):37-52.

13. Contempre B, Je D, Bebe Ngo, Ch T, At D, Vanderpas J. Effect of Selenium Supplementation in Hypothyroid Subjects of An Iodine And Selenium Deficient Area: The Possible Danger of Indiscriminate Supplementation of Iodine-Deficient Subjects with Selenium. J Clin Endocrinol Metab [Internet]. 1991 Jul 1;73(1):213-5. Available from: https: // doi.or g/ 10.1210/jcem-73-1-213

14. Thangaratinam S, Tan A, Knox E, Kilby MD, Franklyn J, Coomarasamy A. Association between thyroid autoantibodies and miscarriage and preterm birth: Meta- analysis of evidence. Bmj.2011;342(7806):1-8.

15. Stagnaro-Green A, Glinoer D. Thyroid autoimmunity and the risk of miscarriage. Best Pract Res Clin Endocrinol Metab. 2004 Jun;18(2):167-81.

16. Pop VJ, de Vries E, van Baar AL, Waelkens JJ, de Rooy HA, Horsten M, et al. Maternal thyroid peroxidase antibodies during pregnancy: a marker of impaired child development? J Clin Endocrinol Metab [Internet]. 1995 Dec 1;80(12):3561-6. Available from: https://doi.org /10.1210/jcem.80.12.8530599

17. Mandel SJ. Hypothyroidism and chronic autoimmune thyroiditis in the pregnant state: maternal aspects. Best Pract Res Clin Endocrinol 
Metab. 2004 Jun;18(2):213-24.

18. Lazarus JH, Ammari F, Oretti R, Parkes AB, Richards CJ, Harris B. Clinical aspects of recurrent postpartum thyroiditis. Br J Gen Pract. 1997 May;47(418):305-8.

19. Glinoer D. What happens to the normal thyroid during pregnancy? Thyroid. 1999 Jul;9(7):631-5.

20. Dauksiene D, Petkeviciene J, Klumbiene J, Verkauskiene R, Vainikonyte-Kristapone J, Seibokaite A, et al. Factors Associated with the Prevalence of Thyroid Nodules and Goiter in Middle-Aged Euthyroid Subjects. Corbetta S, editor. Int $J$ Endocrinol [Internet]. 2017;2017:8401518. Available from: https://doi.org/10.1155/2017/8401518

21. Manji N, Carr-Smith JD, Boelaert K, Allahabadia A, Armitage M, Chatterjee VK, et al. Influences of age, gender, smoking, and family history on autoimmune thyroid disease phenotype. $J$ Clin Endocrinol Metab. 2006;91(12):4873-80.

22. Iddah MA, Macharia BN. Autoimmune Thyroid Disorders. Hu J-F, Skafar DF, editors. ISRN Endocrinol [Internet]. 2013;2013:509764. Available from: https://doi.org/10.1155/2013/509764 